\title{
Effects of salvianolic acid on cerebral perfusion in patients after acute stroke: A single-center randomized controlled trial
}

\author{
JIAN-WEI PENG ${ }^{1}$, YUAN LIU ${ }^{2}$, GAI MENG ${ }^{1}$, JIN-YAN ZHANG ${ }^{1}$ and LIAN-FANG YU ${ }^{3}$ \\ ${ }^{1}$ Department of Neurology, People's Liberation Army 153 Central Hospital, Zhengzhou, Henan 450041; \\ ${ }^{2}$ Postgraduate Department, Xinxiang Medical College, Xinxiang, Henan 453003; ${ }^{3}$ Department of Radiology, \\ People's Liberation Army 153 Central Hospital, Zhengzhou, Henan 450041, P.R. China
}

Received February 20, 2017; Accepted July 2, 2018

DOI: $10.3892 /$ etm.2018.6444

\begin{abstract}
Hypoperfusion following acute stroke is common in the infarct core and periphery tissues. The present study evaluated the efficacy of salvianolic acid (SA) on the cerebral perfusion of patients who had suffered from acute stroke using perfusion-weighted magnetic resonance imaging (PWI) to examine the blood perfusion of the affected brain tissue prior to and following treatment. Patients who were admitted to PLA 153 Central Hospital within $72 \mathrm{~h}$ of acute stroke symptom onset and had a Glasgow coma scale $\geq 5$ were randomized into two groups: SA and control groups. Patients in the SA group were administered SA $0.13 \mathrm{~g} /$ day for 14 days. PWI was performed for all patients at admission and post-treatment. The National Institutes of Health Stroke Scale (NIHSS) and modified Rankin Scale (mRS) were applied to assess neurological function at admission and 3 months post treatment. A total of 159 patients were enrolled (85 patients in the SA group and 74 patients in the control group). A total of 62 patients in the SA group and 51 patients in the control group exhibited hypoperfusion in the ipsihemisphere of the diffusion-weighted magnetic resonance imaging (DWI) lesion. In addition, relative cerebral blood volume (rCBV), a ratio of the signal value of the region of interest in the same hemisphere of the DWI lesion to that of its mirror in the PWI CBV map, decreased significantly following treatment with SA compared with the control group in patients with hypoperfusion $(\mathrm{P}=0.02)$, which were indicated by PWI images at admission, in the DWI lesions or the surrounding areas. Additionally, there was no significant difference in patients with normal perfusion at admission in $\mathrm{rCBV}$ in DWI lesions or its surrounding area between the two groups at day 15 .
\end{abstract}

Correspondence to: Dr Jian-Wei Peng, Department of Neurology, People's Liberation Army 153 Central Hospital, 602 Zhengshang Road, Zhongyuan, Zhengzhou, Henan 450041, P.R. China

E-mail: pengjianwei0923@sina.com

Key words: salvianolic acid, acute stroke, treatment, perfusion-weighted magnetic resonance imaging, cerebral blood volume
However, a significant improvement in NIHSS $(\mathrm{P}=0.001)$ and $\mathrm{mRS}(\mathrm{P}=0.005)$ was indicated in the $\mathrm{SA}$ group compared with the control at day 90 . The present study indicated that SA may improve the neurological dysfunction of patients with acute stroke, which may be explained by the increased perfusion of hypoperfused brain tissues.

\section{Introduction}

The Global Burden of Diseases study 2015 reported a total of 42.43 million cases of cerebrovascular disease worldwide and a total of 6.33 million moralities due to stroke (1). Individuals $>40$ years of age had an increased prevalence of stroke, with the highest rate for those aged 74-79 years. The age-standardized prevalence of ischemic stroke was greater than that of hemorrhagic stroke in the majority of regions and resulted in $57 \%$ of all stroke mortalities in 2015 . The incidence rate was 54/100,000 in males and 44/100,000 in females (1). There was a markedly higher stroke mortality rate in non-Hispanic African-American individuals compared with all other ethnic groups and $>25 \%$ of stroke mortalities in individuals aged $\geq 45$ occurred to those in the 45-64 years age group (28.6\%) (2). In China age-standardized stroke mortality was $127 / 100,000$ individuals in 2010 (3). In the last decade China has observed significant growth in its elderly population and individuals $\geq 75$ years old accounted for $3.5 \%$ of the total population in 2013. Residents $\geq 65$ years old reached 200 million in 2014 and there was a $4.3 \%$ increase in annual first-ever stroke incidence from 1992 to 2012 (4). Stroke is the primary cause of mortality and a prominent factor associated with disability-adjusted life-years in China, with high social and economic costs (5). Therefore urgent investigation into novel therapies for the effective treatment of stroke is required.

Patients with acute stroke suffer from a sudden decrease in cerebral blood flow in partial or global brain tissues, which leads to a reduction in oxygen and glucose supply and ultimately results in permanently infarcted tissue (ischemic core) surrounded by a reversible and salvageable zone (penumbra) (6). The degree and duration of tissue hypoperfusion determines the outcome of the ischemic tissue $(7,8)$. An assessment of penumbral presence may be used to identify patients who are ineligible for acute stroke treatment but may still benefit from reperfusion therapy (9). Various imaging methods may be used 
to assess the presence of penumbral tissue (10), including perfusion weighted magnetic resonance imaging (PWI), diffusion weighted magnetic resonance imaging (DWI) and PWI-DWI mismatch, which is useful for the evaluation of cerebral hemodynamics, particularly in indicating hypoperfusion (11). When abnormal PWI lesions are larger than DWI lesions (PWI $>$ DWI) it represents the existence of penumbra following stroke, as previously described (12). Galinovic et al (13) and Mishra et al (14) demonstrated an association between reperfusion and a positive outcome in patients with a substantial PWI-DWI mismatch. However this was not observed in patients without a PWI-DWI mismatch in cohort studies. At present, the only approved drug for acute ischemic stroke is recombinant tissue plasminogen activator (rtPA), which is administered within a time window of 3-4.5 h (14). However, the majority of patients do not benefit from this therapy as they are typically admitted to hospitals $\sim 4.5 \mathrm{~h}$ after symptom onset or there are contraindications to systemic thrombolysis, including recent major surgery or active bleeding (15). Beyond this time window, a delayed intervention is required. Delayed intervention for acute stroke is defined as therapies beyond the $4.5 \mathrm{~h}$ time window, and are based on the principle of arterial recanalization and rapid reperfusion of the ischemic penumbra (16). Improving microcirculation surrounding the ischemic penumbra has been suggested to be an effective way to prevent ischemic injury to neurons (16).

Salvianolic acid (SA) is an extract of Salvia miltiorrhiza Bunge (Danshen), which is a traditional Chinese medicine that has been used within clinical settings for $>2,000$ years in China (17). Danshen is a perennial herb and within traditional Chinese medicine it is used to improve blood circulation (18). $\mathrm{SA}$ is a compound containing multiple salvianolic acids including, salvianolic acid A and B (19). In previous studies it has been demonstrated that salvianolic acid A and B may have neuroprotective effects in an animal model of ischemia (20). The aim of the present study was to investigate whether SA was able to improve penumbral microcirculation in patients who had suffered from acute stroke.

\section{Patients and methods}

Patients. Diagnosis of acute ischemic stroke was confirmed using diffusion-weighted magnetic resonance imaging (DWI) in 159 patients (117 male and 42 female; age, $60.10 \pm 13.02$ years), who were prospectively recruited between June 2015 and March 2016 at the People's Liberation Army 153 Central Hospital (Zhengzhou, China). Inclusion criteria included $<72 \mathrm{~h}$ from symptom onset, a Glasgow coma scale (GCS) score $>5$ (21) and patients without contraindications for magnetic resonance imaging (MRI), including those who were not allergic to paramagnetic contrast agents. Patients with cerebral hemorrhage, resuscitated encephalopathy, or a GCS score $\leq 4$ were excluded from the present study. Written informed consent was obtained from all patients and the present study was approved by the Ethics Committee of PLA 153 Central Hospital (Zhengzhou, China).

Patients were randomly divided into the SA group $(n=85)$ and the control group $(n=74)$. In the control group, patients were treated with standard therapy, which was aspirin enteric-coated tablets 100 mg/day (Bayer AG, Leverkusen, Germany) and atorvastain tablets $20 \mathrm{mg}$ /day (Pfizer, Inc., New York, NY, USA). Patients continued to be treated with drugs for pre-existing conditions, including hypertension and diabetes mellitus. The control group was treated with a total of $250 \mathrm{ml}$ normal saline administered intravenously everyday for 14 days. In the SA group, SA (0.13 g/day; Tasly Pharmaceutical Group Co., Ltd., Tianjin, China) was administered intravenously dissolved in $250 \mathrm{ml}$ normal saline for 14 days in addition to the standard therapy as performed in the control group. If the patient was eligible for rtPA thrombolysis (symptom onset to treatment $\leq 3 \mathrm{~h}$ and no bleeding at admission), intravenous rtPA treatment $(0.9 \mathrm{mg} / \mathrm{kg}$; Boehringer Ingelheim International $\mathrm{GmbH}$, Ingelheim am Rhein, Germany) was received whether in the control or SA group. One patient received rtPA treatment in each group.

Magnetic resonance imaging. All images were acquired on a Siemens $3 \mathrm{~T}$ whole body Trio scanner (Siemens Healthineers, Erlangen, Germany). The MRI protocol included DWI, fluid-attenuated inversion recovery (FLAIR) and dynamic susceptibility contrast perfusion perfusion-weighted MRI (PWI). DWI, FLAIR and PWI were performed on day 1 or 2 of admission, and DWI and PWI were repeated post-admission on day 15.

DWI was obtained with the use of a multislice, single-shot, spin-echo echo-planar imaging sequence with the following parameters: Time of repetition (TR), 4,200 $\mathrm{msec}$; time of echo (TE), $96 \mathrm{msec}$; field of view (FOV), 24x24 cm; and matrix size, $256 \times 256$. A total of $216-\mathrm{mm}$ thick slices with a $10 \%$ gap were obtained, and these images were collected with $\mathrm{b}=1,000 \mathrm{~s} / \mathrm{mm}^{2}$, from which the apparent diffusion coefficient was determined.

The following FLAIR sequence parameters were used: TR, 6,500 msec; TE, $110 \mathrm{msec}$; inversion time, 2,200 msec; FOV, 24x $24 \mathrm{~cm}$; and matrix 256x256, for 216 -mm thick slices with a $10 \%$ gap.

For PWI, a gradient echo, echo planar imaging sequence was employed. Gadolinium diethylenetriaminepentaacetic acid (Gd-DTPA; Guangzhou Consun Pharmaceutical, Co., Ltd., Guangzhou, China) at $0.2 \mathrm{mmol} / \mathrm{kg}$ was administered using a large-bore cannula $(20 \mathrm{G} ; 1.1 \times 30 \mathrm{~mm})$ in the antecubital fossa (speed, $5 \mathrm{ml} / \mathrm{sec}$ ) through a power injector (Medrad Inc.; Bayer, Newbury, UK), followed by $20 \mathrm{ml}$ normal saline with the same speed. A total of 19 slices were obtained with a slice thickness of $5 \mathrm{~mm}$ and a $30 \%$ gap (FOV, 23x23 cm; matrix, 128x128; TR, 1,550 msec; and TE, $32 \mathrm{msec})$. At the end of the third scanning procedure of 50 continuous scans with a total scanning time $84 \mathrm{sec}$, a bolus injection of Gd-DTPA was administered. Subsequently, images were obtained at 50 time points per slice, with a total of 950 images. The raw PWI data were processed using an MRI workstation (Siemens Healthineers) to produce PWI maps, including cerebral blood volume (CBV), cerebral blood flow (CBF), mean transit time (MTT) and time to peak (TTP) maps. On these maps the abnormal perfusion was expressed as red, making it easily identified by the naked eye, which is known as the visual assessment method.

Manual imaging coregistration. Slices with the most notable changes in DWI were selected, and non-transparent and reverse 

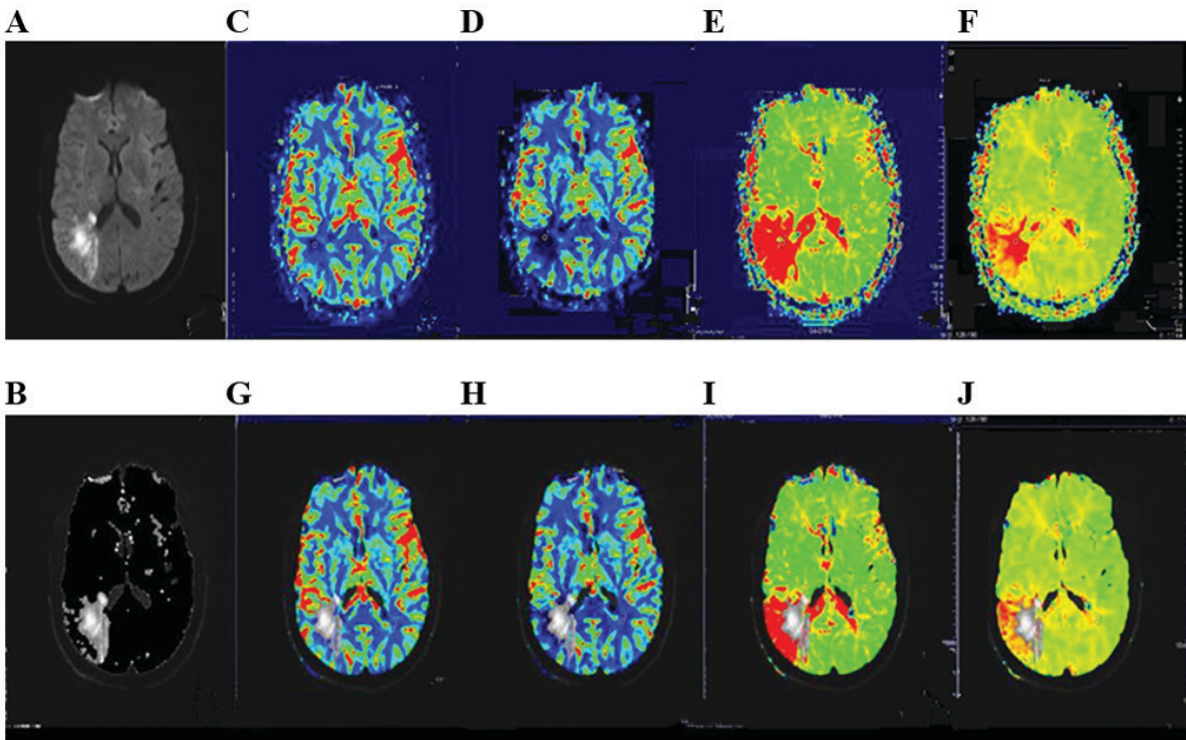

Figure 1. Illustration of manual imaging registration. (A) DWI image was processed into a non-transparent image and indicated the DWI lesion. (B) A transparent image was processed using photo processing. (C-F) Processed image was superimposed on the PWI maps. (G-J) Coregistered images were subsequently produced. DWI, diffusion-weighted magnetic resonance imaging.

A

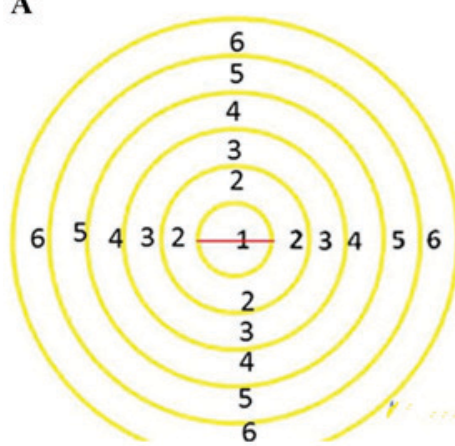

C

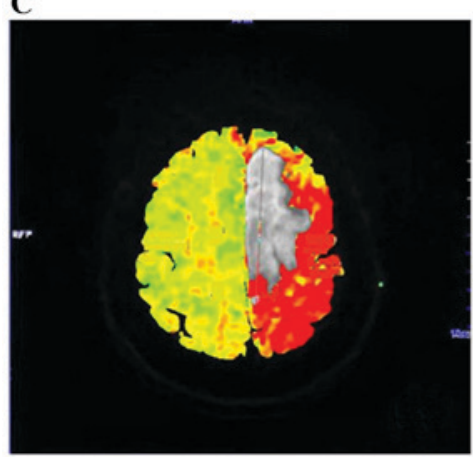

B

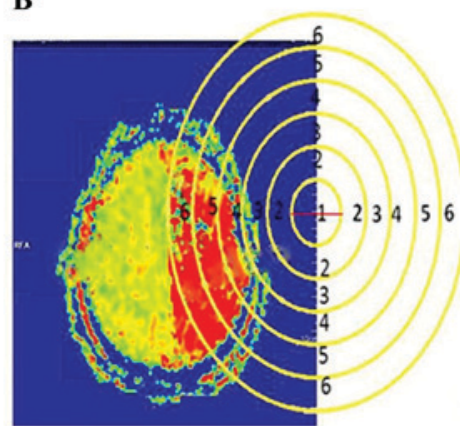

D

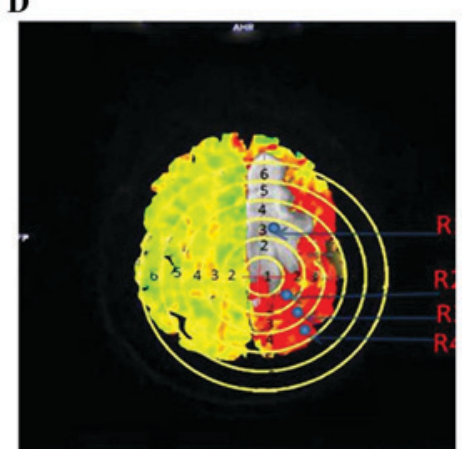

Figure 2. Demonstration of the concentric circle calibration. (A) The concentric circle consisted of six circles with a $1 \mathrm{~cm}$ diameter difference value and was superimposed on the ruler of the PWI map to identify a magnification of x2. (B) The processed DWI image (C) coregistered the image with the PWI map. Following the placing of the innermost circle of the concentric circle on the border of the DWI lesion in order to locate the distance of region of interest from the DWI lesion. (D) R1 was located in the DWI lesion; R2, R3, and R4 were 1, 2 and $3 \mathrm{~cm}$ from DWI lesion, respectively. R, region of interest; DWI, diffusion-weighted magnetic resonance imaging; PWI, perfusion-weighted magnetic resonance imaging.

conversions were performed on the DWI lesions that were identified as diaphanous via photo processing (Photoshop CS5; Adobe Systems, Inc., San Jose, CA, USA). Subsequently, the processed images were superimposed on the same or the nearest slice of the PWI map with the same magnification; and imaging coregistration was completed (Fig. 1).
Definitions. The $0.16-\mathrm{cm}^{2}$ area selected on the ipsilateral hemisphere of the DWI lesion on the PWI maps was defined as the region of interest (ROI). ROIs were located either in the lesion or in its surrounding tissue using coregister imaging. The signal intensity of ROI was calculated automatically (Syngo ${ }^{\circledR}$ MR B17; Siemens AG, Munich, Germany) on CBV, 
Table I. Clinical characteristics of patients.

\begin{tabular}{lccc}
\hline Characteristic & SA & Control & P-value \\
\hline Patients (n) & 85 & 74 & 0.47 \\
Sex (n; male/female) & $65 / 20$ & $52 / 22$ & 0.52 \\
Age (years) & $60.07 \pm 12.96$ & $20.10 \pm 24.10$ & 0.77 \\
Symptom onset (h) & $17.33 \pm 20.05$ & $12.13 \pm 1.89$ & 0.85 \\
GCS at admission & $12.27 \pm 1.91$ & $61 / 13$ & 0.91 \\
Responsibility vessels (ICA/VBA) & $69 / 14$ & $51 / 23$ & 0.60 \\
Ipsilateral hypoperfusion (positive/negative) & $62 / 23$ & $5 / 69$ & 0.05 \\
Contralateral hypoperfusion (positive/negative) & $15 / 70$ & $3 / 71$ & 0.22 \\
Contralateral DWI lesion (positive/negative) & $8 / 77$ &
\end{tabular}

${ }^{\mathrm{a} O f}$ the total number of patients, 2 cases were not included, which involved both ICA and VBA. SA, salvianolic acid; ICA, internal carotid artery; VBA, vertebral basilar artery; GCS, Glasgow coma scale; DWI, diffusion-weighted magnetic resonance imaging.

CBF, MTT and TTP maps, respectively. A mirror of the ROI with the same area was placed on the contralateral hemisphere symmetrically with avoidance of vessel and cortical sulci, and its signal intensity was also calculated automatically (Syngo ${ }^{\circledR}$ MR B17).

To perform circle calibrations, six circles with diameters of 1, 2, 3, 4, 5 and $6 \mathrm{~cm}$, were drawn to form a concentric circle. Subsequently, the concentric circle was placed on the ruler of the PWI maps to identify the magnification factor. The minimum circle of the concentric circle thereafter was placed on the border of the DWI lesion on the coregistered PWI map. A 2-3 cm distance from the border of the DWI lesion was defined as the lesion surroundings, where ROIs represented the ischemic penumbra (Fig. 2).

Furthermore, the ratio of the signal value of ROI in the injured hemisphere to that of its mirror was considered to indicate the relative PWI parameter, that is, relative (r)CBV, rCBF, rMTT and rTTP.

According to the territory of arterial supplies, the internal cranial artery (ICA) was defined as the responsibility vessel when the DWI lesion was located in ICA territory. Similarly, the vertebral basilar artery (VBA) was defined as the responsibility vessel when there was a DWI lesion in its territory.

Due to the reversed association of the signal value with the real $\mathrm{CBV}, \mathrm{CBV}$ may be reasonably speculated from $\mathrm{rCBV}$ as follows: If $\mathrm{rCBV}$ was $<1$, meaning that the blood perfusion in ROI was greater than that in it's mirror, the speculated $\mathrm{CBV}=[1+(1-\mathrm{rCBV})] \times 100 \%$; whereas, if $\mathrm{rCBV}$ was $>1$, meaning that the blood perfusion in ROI was less than that in it's mirror, the speculated $\mathrm{CBV}=[1-(\mathrm{rCBV}-1)] \times 100 \%$.

The modified Rankin Scale (mRS) (22) was used to measure the extent of disability in patients after stroke with ordinal scores from 0-6 as follows: 0 , no symptoms or disability; 1, symptoms but no disability; 2, slight disability but no assistance was required; 3 , moderate disability and some assistance was required with activities of daily living, but patients were able to walk independently; 4, moderately severe disability and inability to walk or care for bodily requirements without assistance; 5 , severe disability where patients were bedridden and required constant care; and 6 , patients succumbed to fatality. An mRS score of 0-2 was considered a favorable outcome and scores $\geq 3$ were considered as unfavorable. $\mathrm{mRS}$ scores were recorded in all patients at the 3-month follow-up.

The National Institutes of Health Stroke Scale (NIHSS) (23) was applied to measure the extent of neurological dysfunction or deficit after stroke across multiple domains, including motor, sensory, visual and language functions. Scores ranged from $0-42$, with a higher score indicating a more severe neurological deficit. NIHSS was recorded at admission and the 3-month follow-up.

Statistical analysis. All data were presented as mean \pm standard deviation, and IBM SPSS software (version 19.0; IBM Corp., Armonk, NY, USA) was applied for statistical analysis of the data. Independent or unpaired sample t-test was used to compare the differences between the groups mean values. The constitutive ratio was analyzed using Fisher's exact test. $\mathrm{P}<0.05$ was considered to indicate a statistically significant difference.

\section{Results}

Clinical characteristics. Among the total 168 patients that were screened, 4 patients were excluded from the study due to allergy to sulfanilamide $(n=2)$ and claustrophobia $(n=2)$. A total of 5 patients in the control group dropped out from the trial due to the requirement of the patients to transfer to another hospital during treatment.

Baseline characteristics of the patients are indicated in Table I. Among the 159 patients, 85 patients were allocated to the SA group and 74 patients were allocated to the control group. No statistically significant differences were identified regarding the sex, age, and time from symptom onset to hospital admission between the control and SA groups. The median time from symptom onset to hospital admission was $6 \mathrm{~h}$ in the SA group and $9 \mathrm{~h}$ in the control group. Furthermore, the median GCS at admission was $\sim 12$ in the SA and control groups.

Through visual assessment (24) 62 patients in the SA group and 51 patients in the control group were recorded as exhibiting hypoperfusion at admission. In addition, 
Table II. Relative perfusion-weighted magnetic resonance imaging parameters of the diffusion-weighted magnetic resonance imaging lesion at admission.

\begin{tabular}{lcccc}
\hline Group & rCBV & rCBF & rMTT & rTTP \\
\hline SA & $1.27 \pm 0.59$ & $0.68 \pm 0.45$ & $1.31 \pm 0.56$ & $1.17 \pm 0.24$ \\
Control & $1.21 \pm 0.68$ & $0.85 \pm 0.51$ & $1.34 \pm 0.56$ & $1.15 \pm 0.36$ \\
P-value & 0.62 & 0.08 & 0.73 & 0.73 \\
\hline
\end{tabular}

$\mathrm{rCBV}$, relative cerebral blood volume; $\mathrm{rCBF}$, relative cerebral blood flow; rMTT, regional mean transit time; rTTP, regional time to peak; SA, salvianolic acid.

Table III. Relative perfusion-weighted magnetic resonance imaging parameters of the surrounding region of the diffusion-weighted magnetic resonance imaging lesion at admission.

\begin{tabular}{lcccc}
\hline Group & rCBV & rCBF & rMTT & rTTP \\
\hline SA & $1.02 \pm 0.56$ & $0.80 \pm 0.35$ & $1.32 \pm 0.57$ & $1.05 \pm 0.17$ \\
Control & $1.01 \pm 0.55$ & $0.84 \pm 0.51$ & $1.44 \pm 0.71$ & $1.14 \pm 0.29$ \\
P-value & 0.82 & 0.61 & 0.31 & 0.09 \\
\hline
\end{tabular}

rCBV, relative cerebral blood volume; $\mathrm{rCBF}$, relative cerebral blood flow; rMTT, regional mean transit time; rTTP, regional time to peak; SA, salvianolic acid.

23 patients exhibited normal perfusion in both the control and SA groups; however, contralateral hypoperfusion occurred in 15 patients in the SA group and 5 patients in the control group. No significant difference was indicated in ipsilateral hypoperfusion between the control or SA groups in the constitutive ratio (Table I). Additionally, the results indicated that there was no significant difference in contralateral DWI lesion between the control and SA groups. The present findings suggested that the ICA was associated with 69 cases in the SA group and 61 cases in the control group. Furthermore, 14 cases in the SA group and 13 cases in the control group were verified VBA as the responsible artery. The remaining 2 patients in the SA group had DWI lesions in both ICA and VBA territories.

Changes of relative PWI parameters at admission. The relative PWI parameters at admission within DWI lesions, which were located using the coregister imaging method, were indicated to be $<1$ for $\mathrm{rCBF}(0.68 \pm 0.45$ in the SA group vs. $0.85 \pm 0.51$ in the control group), and $>1$ for rMTT $(1.31 \pm 0.56$ in the SA group vs. $1.34 \pm 0.56$ in the control group) and rTTP $(1.17 \pm 0.24$ in the SA group vs. $1.15 \pm 0.36$ in the control group) (Table II). In addition, the mean rCBV was $1.27 \pm 0.59$ in the SA group and $1.21 \pm 0.68$ in the control group. Due to the reversed association of the signal value with the real CBV (25), the value of $\mathrm{rCBV}>1$ implied hypoperfusion compared with its contralateral hemisphere. Changes in the relative PWI parameters indicated that hypoperfusion and longer blood perfusion times were similar in the DWI lesions of SA and control groups (Table II). Table III demonstrated similar observations of the relative PWI parameters regarding the environment surrounding the DWI lesion, which was limited in $1-3 \mathrm{~cm}$ around the lesion using the concentric circle calibration method; and similar hypoperfusion and longer blood perfusion times were also indicated. Results suggested there was no significant difference identified in $\mathrm{rCBV}, \mathrm{rCBF}$, rMTT and rTTP between the SA and control groups.

In either ICA or VBA, there were no significant differences in $\mathrm{rCBV}$, rCBF, rMTT, or rTTP between the SA and control groups in the DWI lesion or in its surroundings (Table IV); which indicated a similar effect was observed regarding the relative PWI parameters between SA and control groups. In normal perfusion or hypoperfusion, the relative PWI parameters were not significantly different in the DWI lesion or in its surroundings in the SA and control groups at admission (Table V).

Changes in relative PWI parameters following treatment. There was no significant differences identified between the SA and control groups post-treatment in terms of rCBV, rCBF, rMTT, and rTTP in the DWI lesion or its surroundings (Figs. 3 and 4, respectively). However, compared with the different responsible vessel, there was a significant difference between the two groups in ICA in rCBV, rCBF, and rMTT (Figs. 5 and 6); however, there was no significant difference in VBA (Figs. 7 and 8), which implied a superior treatment effect on ICA to VBA. Comparisons of the perfusion states indicated there was no significant difference in normal perfusion (Figs. 9 and 10). However, a significant difference appeared in the hypoperfusion between the two groups in rCBV, rCBF, rMTT, and rTTP, either in the DWI lesion or in its surrounding (Figs. 11 and 12). These findings indicate that patients with hypoperfusion at admission may benefit from this therapy to a greater extent compared with patients with normal perfusion.

In certain patients the abnormal PWI disappeared following treatment with SA, whereas in other patients treated with SA abnormal PWI persisted (Fig. 13). This may be due to the different reperfusion of CBV.

Speculated CBV using the speculation method. The CBV at admission in the DWI lesion was 73 and $79 \%$ of the contralateral in the SA and control groups, respectively (Table VI). In addition, surrounding the DWI lesion the CBV was 98 and $99 \%$ of the contralateral in the SA and control groups, respectively (Table VII). However, in patients with hypoperfusion at admission the CBV was 93 and $46 \%$ of the contralateral in the DWI lesions and 102 and $61 \%$ in the surroundings in the SA and control groups, respectively following treatment (Table VIII). In patients with ICA responsible artery the CBV was 98 and 50\% in the DWI lesions and 104 and 67\% in the surroundings following treatment in the SA and control groups, respectively (Table IX).

Neurological function. The neurological function in patients was evaluated using NIHSS and mRS. There was no significant difference in NIHSS between the two groups at admission $(8.43 \pm 6.05$ in the SA group vs. $9.12 \pm 5.98$ in the control group; 
Table IV. Relative PWI parameters with different responsibility vessels at admission.

\begin{tabular}{|c|c|c|c|c|}
\hline \multicolumn{5}{|l|}{ A, ICA } \\
\hline Vessels & $\mathrm{rCBV}$ & $\mathrm{rCBF}$ & rMTT & rTTP \\
\hline \multicolumn{5}{|c|}{ DWI lesion } \\
\hline $\mathrm{SA}$ & $1.27 \pm 0.58$ & $0.72 \pm 0.49$ & $1.40 \pm 0.59$ & $1.19 \pm 0.23$ \\
\hline Control & $1.24 \pm 0.73$ & $0.82 \pm 0.47$ & $1.39 \pm 0.60$ & $1.15 \pm 0.39$ \\
\hline P-value & 0.82 & 0.35 & 0.96 & 0.57 \\
\hline \multicolumn{5}{|c|}{ Surrounding of DWI lesion } \\
\hline $\mathrm{SA}$ & $1.02 \pm 0.58$ & $0.78 \pm 0.37$ & $1.37 \pm 0.57$ & $1.08 \pm 0.14$ \\
\hline Control & $1.02 \pm 0.60$ & $0.80 \pm 0.54$ & $1.56 \pm 0.76$ & $1.16 \pm 0.32$ \\
\hline P-value & 0.96 & 0.89 & 0.20 & 0.20 \\
\hline
\end{tabular}

$\mathrm{B}, \mathrm{VBA}$

\section{DWI lesion}

$\begin{array}{lcccc}\text { SA } & 1.26 \pm 0.68 & 0.56 \pm 0.24 & 1.00 \pm 0.33 & 1.08 \pm 0.25 \\ \text { Control } & 1.07 \pm 0.40 & 0.84 \pm 0.40 & 1.15 \pm 0.26 & 1.12 \pm 0.27 \\ \text { P-value } & 0.47 & 0.07 & 0.26 & 0.71\end{array}$

Surrounding of DWI lesion

\begin{tabular}{lcccc} 
SA & $1.06 \pm 0.54$ & $0.83 \pm 0.29$ & $1.18 \pm 0.56$ & $0.95 \pm 0.25$ \\
Control & $0.90 \pm 0.29$ & $1.00 \pm 0.38$ & $1.01 \pm 0.15$ & $1.06 \pm 0.15$ \\
P-value & 0.39 & 0.24 & 0.32 & 0.20 \\
\hline
\end{tabular}

rCBV, relative cerebral blood volume; rCBF, relative cerebral blood flow; rMTT, regional mean transit time; rTTP, regional time to peak; SA, salvianolic acid. SA, salvianolic acid; ICA, internal carotid artery; VBA, vertebral basilar; DWI, diffusion-weighted magnetic resonance imaging.
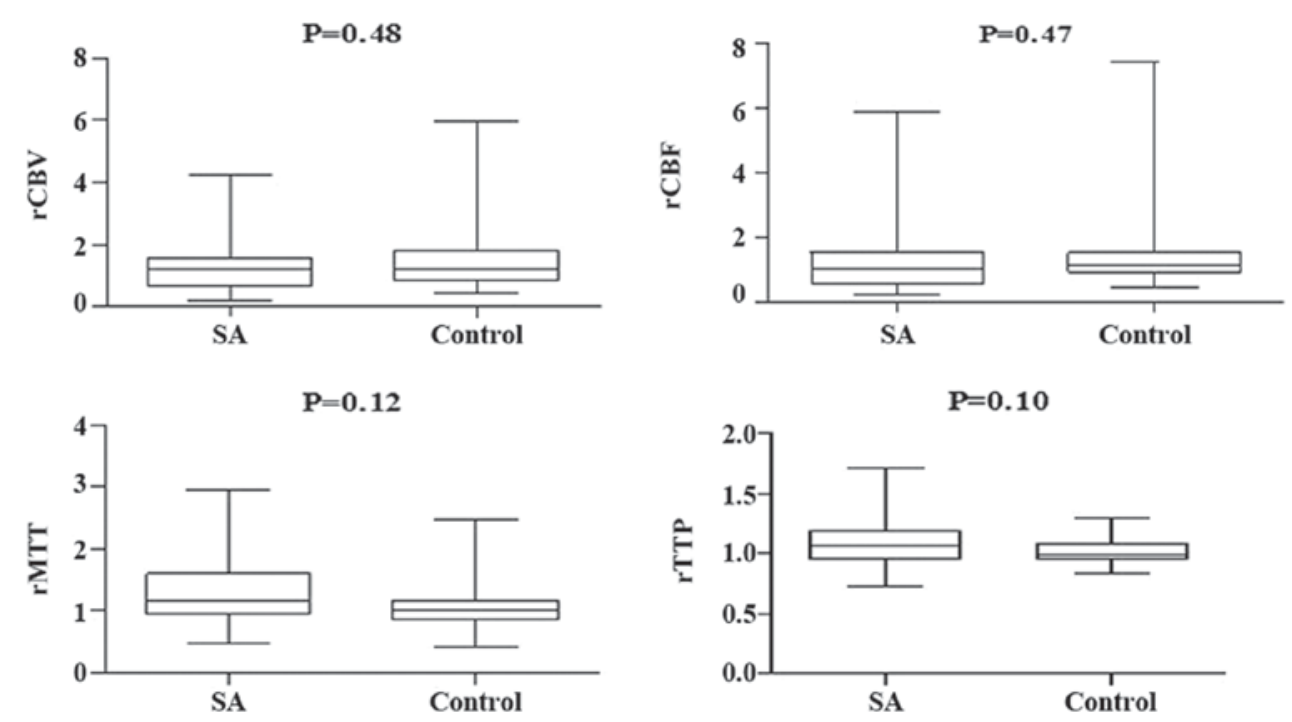

Figure 3. Relative perfusion-weighted magnetic resonance imaging parameters of the diffusion-weighted magnetic resonance imaging lesion in hypoperfused patients after 14-days of treatment. rCBV, relative cerebral blood volume; rCBF, relative cerebral blood flow; rMTT, regional mean transit time; rTTP, regional time to peak; SA, salvianolic acid.

$\mathrm{P}=0.47$; Table X). However, at the 3-month follow-up, NIHSS in the SA group was significantly decreased compared with that in the control group ( $3.25 \pm 4.67$ vs. $5.76 \pm 3.82 ; \mathrm{P}=0.001)$, and $\mathrm{mRS}$ was also significantly reduced in the $\mathrm{SA}$ group $(1.26 \pm 1.58$ vs. $2.01 \pm 1.58, \mathrm{P}=0.005$ (Table $\mathrm{X})$, which indicated that there was a minor deficit of neurological function in the SA group compared with that in the control group. When mRS was dichotomized, the proportion of patients with a favorable outcome was significantly increased in the SA group compared with the control group (Fig. 14). 
Table V. Relative PWI parameters with different perfusion state at admission.

A, Normal perfusion

\begin{tabular}{|c|c|c|c|c|}
\hline Perfusion state & $\mathrm{rCBV}$ & $\mathrm{rCBF}$ & rMTT & rTTP \\
\hline \multicolumn{5}{|l|}{ DWI lesion } \\
\hline SA & $0.88 \pm 0.39$ & $0.92 \pm 0.41$ & $1.09 \pm 0.37$ & $1.01 \pm 0.08$ \\
\hline Control & $0.74 \pm 0.28$ & $1.20 \pm 0.64$ & $1.02 \pm 0.14$ & $0.98 \pm 0.05$ \\
\hline P-value & 0.30 & 0.20 & 0.53 & 0.35 \\
\hline \multicolumn{5}{|c|}{ Surrounding of DWI lesion } \\
\hline $\mathrm{SA}$ & $0.77 \pm 0.26$ & $1.01 \pm 0.42$ & $1.00 \pm 0.18$ & $0.99 \pm 0.09$ \\
\hline Control & $0.79 \pm 0.35$ & $1.01 \pm 0.56$ & $1.03 \pm 0.29$ & $1.04 \pm 0.15$ \\
\hline P-value & 0.90 & 0.10 & 0.77 & 0.32 \\
\hline
\end{tabular}

\section{B, Hypo-Perfusion}

\section{DWI lesion}

\begin{tabular}{lcccc} 
SA & $1.35 \pm 0.40$ & $0.60 \pm 0.41$ & $1.37 \pm 0.59$ & $1.21 \pm 0.25$ \\
Control & $1.38 \pm 0.70$ & $0.72 \pm 0.39$ & $1.47 \pm 0.61$ & $1.15 \pm 0.22$ \\
P-value & 0.82 & 0.22 & 0.47 & 0.26 \\
Surrounding of DWI lesion & & & & \\
SA & $1.11 \pm 0.60$ & $0.73 \pm 0.30$ & $1.42 \pm 0.61$ & $1.18 \pm 0.21$ \\
Control & $1.110 \pm 0.61$ & $0.72 \pm 0.39$ & $1.63 \pm 0.69$ & $1.26 \pm 0.26$ \\
P-value & 0.96 & 0.92 & 0.16 & 0.17 \\
\hline
\end{tabular}

rCBV, relative cerebral blood volume; rCBF, relative cerebral blood flow; rMTT, regional mean transit time; rTTP, regional time to peak; SA, salvianolic acid.
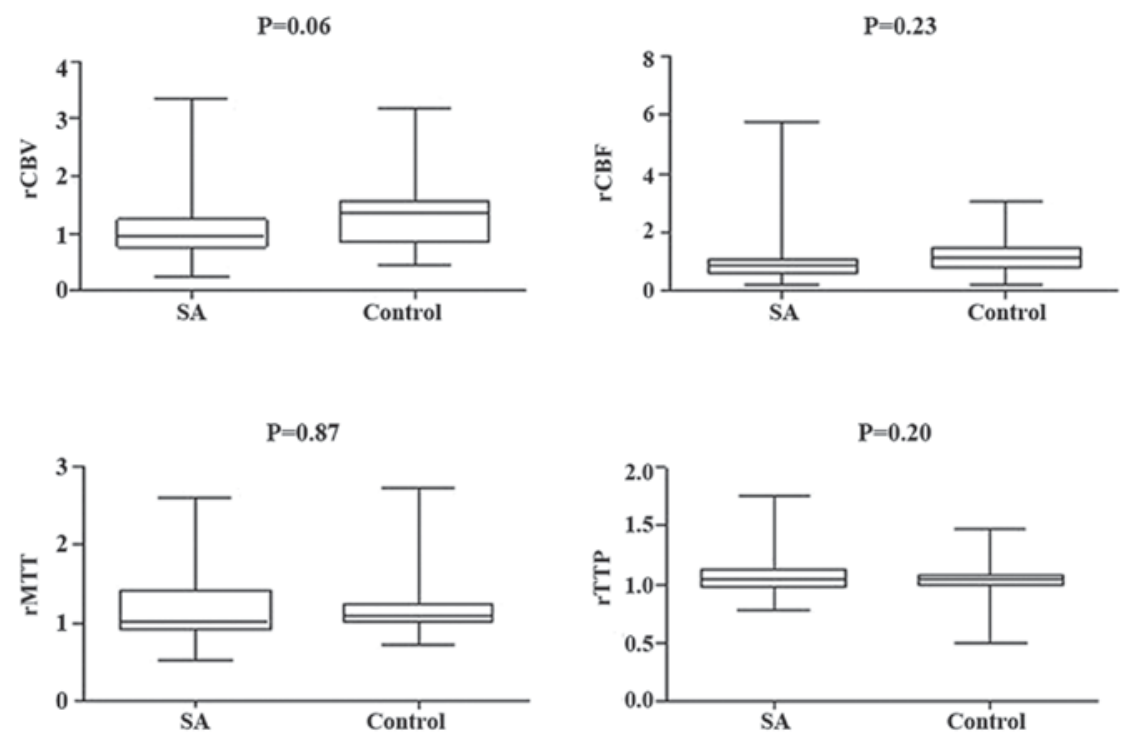

Figure 4. Relative perfusion-weighted magnetic resonance imaging parameters of the surrounding region of the diffusion-weighted magnetic resonance imaging lesion in hypoperfused patients after 14 days of treatment. rCBV, relative cerebral blood volume; rCBF, relative cerebral blood flow; rMTT, regional mean transit time; rTTP, regional time to peak; SA, salvianolic acid.

\section{Discussion}

Stroke is one of the leading causes of morbidity and the second most common cause of mortality worldwide (26). An acute ischemic stroke occurs due to occlusion or a severe restriction in the blood supply to the brain, resulting in hypoperfusion of the brain tissue, namely, ischemic penumbra; which may cause permanent infarction (14). Therefore, the aim of acute stroke treatment is to restore the blood supply of hypoperfused brain tissues in a timely manner to prevent these tissues from undergoing 
$P=0.04$

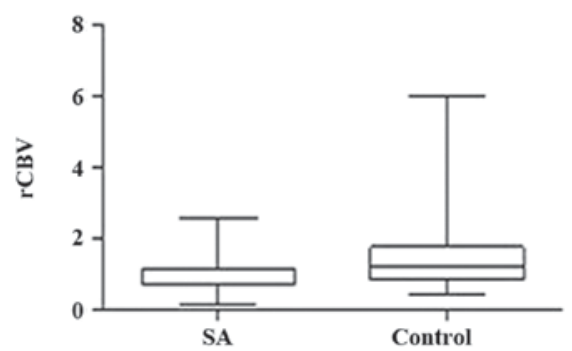

$\mathrm{P}=0.09$

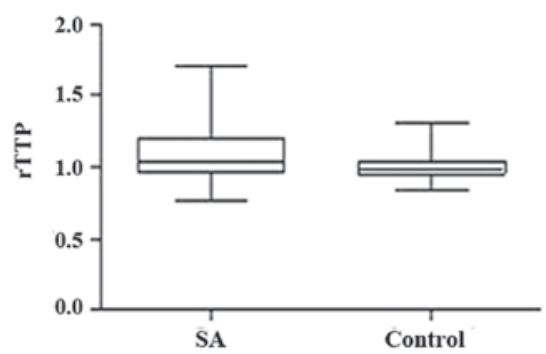

$\mathrm{P}=\mathbf{0 . 0 2}$

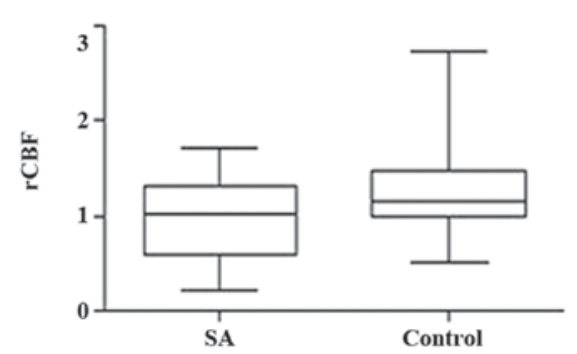

$\mathrm{P}=\mathbf{0 . 0 3}$

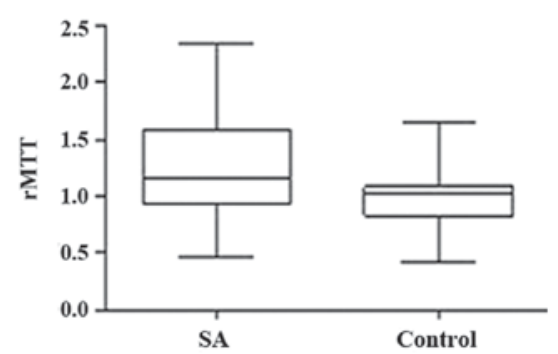

Figure 5. Relative perfusion-weighted magnetic resonance imaging parameters of the diffusion-weighted magnetic resonance imaging lesion in responsibility vessel internal cranial artery after 14 days of treatment. rCBV, relative cerebral blood volume; rCBF, relative cerebral blood flow; rMTT, regional mean transit time; rTTP, regional time to peak; SA, salvianolic acid.
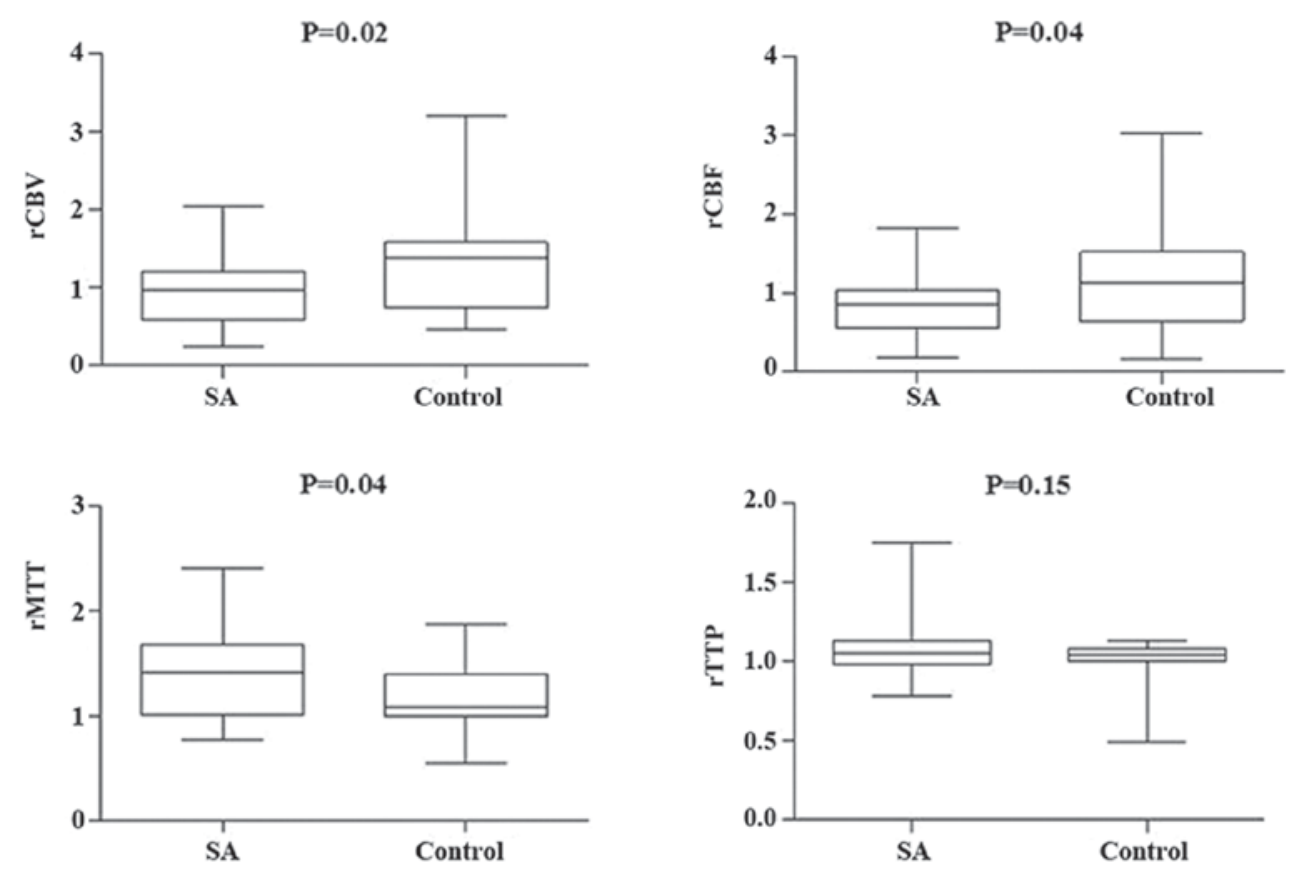

Figure 6. Relative perfusion-weighted magnetic resonance imaging parameters of the surrounding region of the diffusion-weighted magnetic resonance imaging lesion in responsibility vessel internal cranial artery after 14 days of treatment. rCBV, relative cerebral blood volume; rCBF, relative cerebral blood flow; rMTT, regional mean transit time; rTTP, regional time to peak; SA, salvianolic acid.

irreversible injury. This is referred to as reperfusion therapy (13). Currently, effective reperfusion therapy includes the intravenous and intraarterial administration of rtPA, and the use of various thrombectomy devices under X-ray guidance which is typically defined as dethrombosis therapy or recanalization (27-32). The focus of these therapies is on the restoration of the antegrade flow of the supplying artery in the ischemic regions. However, the time window limits its use in clinical practice $(33,34)$.
With the progress of neuroimaging techniques, it is possible to observe the existence of ischemic penumbra. Previous studies have suggested that the mismatch between PWI and DWI represents ischemic penumbra $(35,36)$. If increased CBV in the penumbra is achieved following treatment, it may be concluded that there was a restoration of blood perfusion in the penumbra, whether antegrade or retrograde flow. 

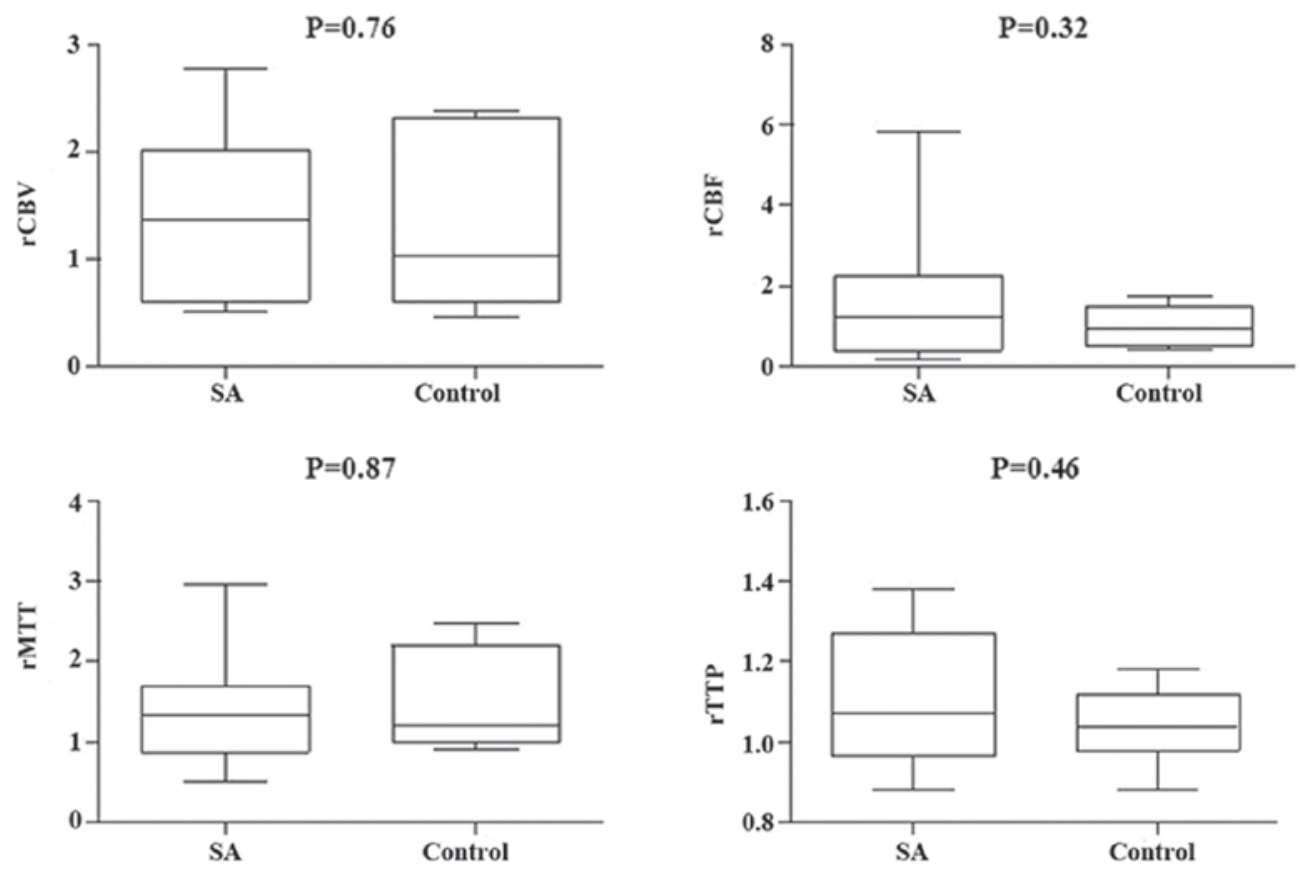

Figure 7. Relative perfusion-weighted magnetic resonance imaging parameters of the diffusion-weighted magnetic resonance imaging lesion in responsibility vessel vertebral basilar artery after 14 days of treatment. $\mathrm{rCBV}$, relative cerebral blood volume; rCBF, relative cerebral blood flow; rMTT, regional mean transit time; rTTP, regional time to peak; SA, salvianolic acid.
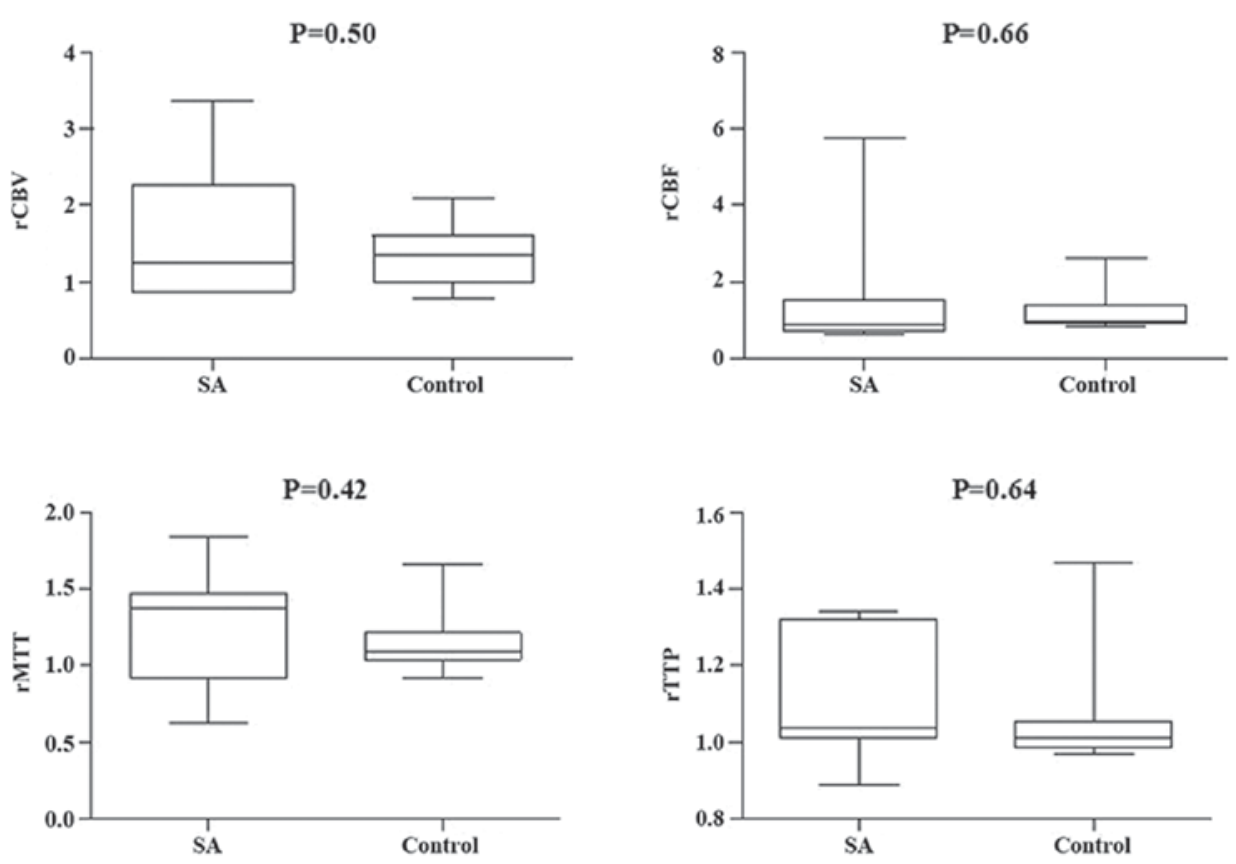

Figure 8. Relative perfusion-weighted magnetic resonance imaging parameters of the surrounding region of the diffusion-weighted magnetic resonance imaging lesion in responsibility vessel vertebral basilar artery after 14 days of treatment. rCBV, relative cerebral blood volume; rCBF, relative cerebral blood flow; rMTT, regional mean transit time; rTTP, regional time to peak; SA, salvianolic acid.

In the present study, among the 159 cases of acute ischemic stroke, 62 cases in the SA group and 51 cases in the control group exhibited hypoperfusion in the ipsilateral hemisphere of the DWI lesion, with another 23 cases in each group who presented with normal perfusion. However, the hypoperfusion/normal perfusion in the ipsilateral hemisphere between these two groups was not significantly different at admission. In addition, relative PWI parameter comparisons between the SA and control groups also indicated no significant difference at admission, whether in DWI lesion or in the surroundings of the DWI lesion. However, following the 14-day treatment, a significant decrease in rCBV occurred in the SA group compared with the control in the DWI lesion and its surrounding region in patients with responsibility vessel ICA or hypoperfusion at admission. Relative PWI parameters in the SA group were compared with those in controls within 

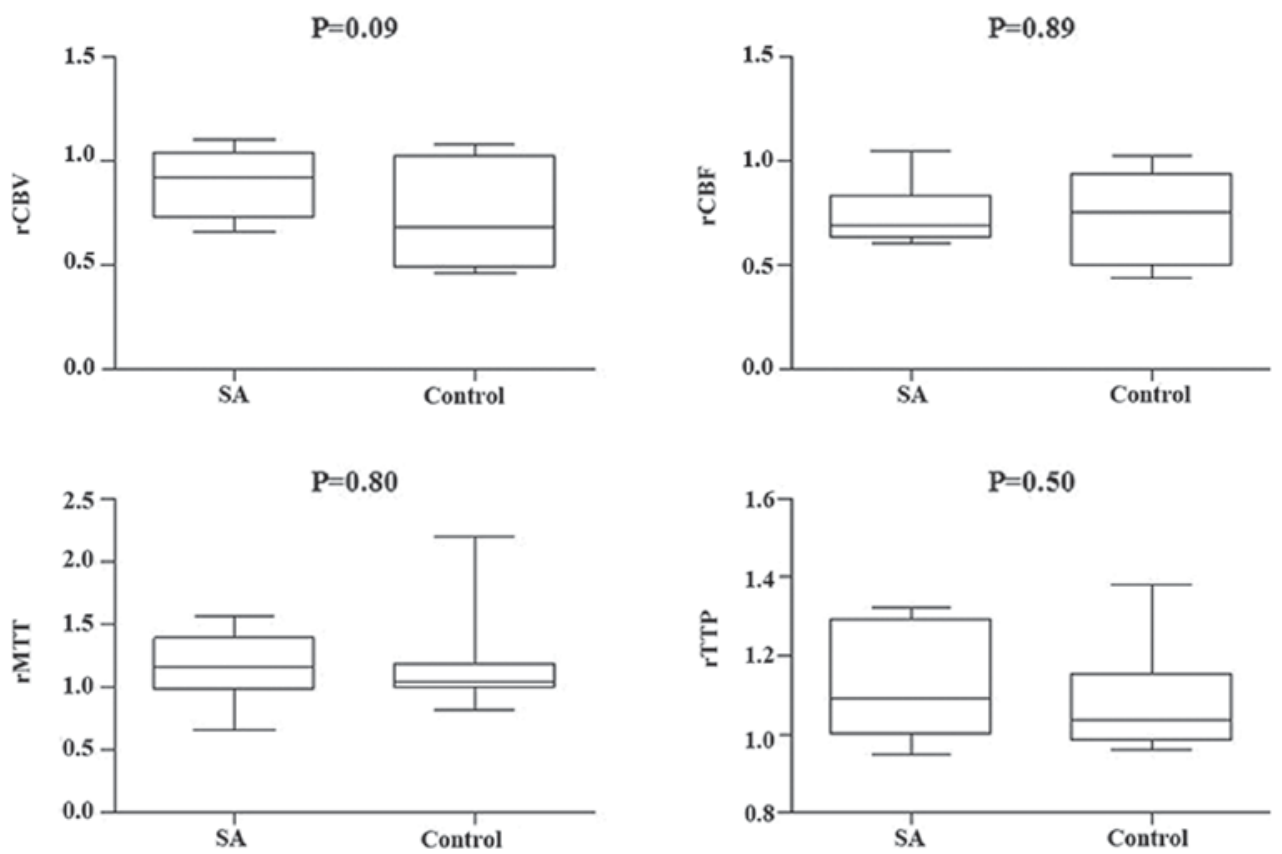

Figure 9. Relative perfusion-weighted magnetic resonance imaging parameters of the diffusion-weighted magnetic resonance imaging lesion in normal perfusion patients after 14 days of treatment. rCBV, relative cerebral blood volume; rCBF, relative cerebral blood flow; rMTT, regional mean transit time; rTTP, regional time to peak; SA, salvianolic acid.
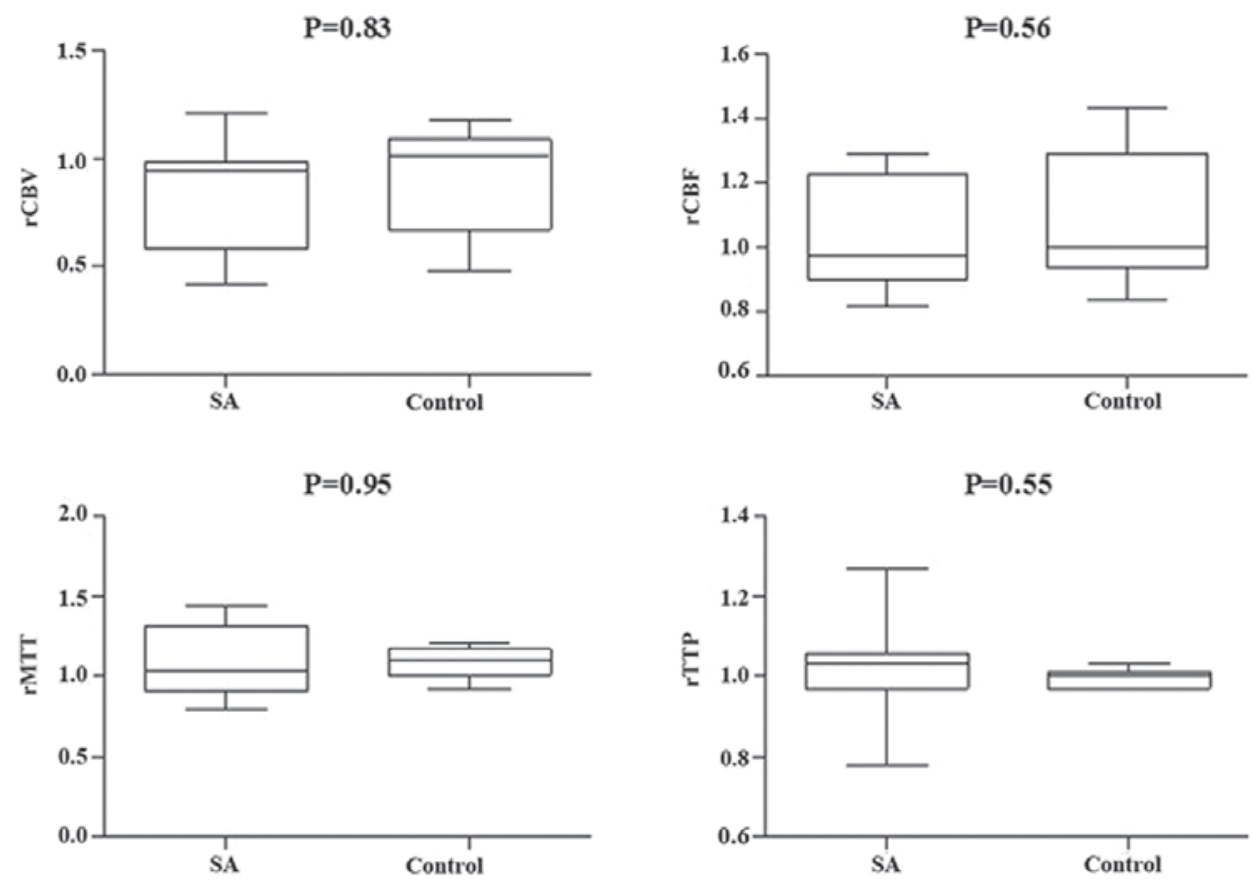

Figure 10. Relative perfusion-weighted magnetic resonance imaging parameters of the surrounding region of the diffusion-weighted magnetic resonance imaging lesion in normal perfusion patients after 14 days of treatment. rCBV, relative cerebral blood volume; rCBF, relative cerebral blood flow; rMTT, regional mean transit time; rTTP, regional time to peak; SA, salvianolic acid.

the subgroups of ICA as a responsible vessel or hypoperfused patients at admission. No significant difference was indicated within the subgroup of VBA as the responsible vessel or normal perfused patients at admission, which implied that SA improved the perfusion of the hypoperfused brain tissue in the DWI lesion and its surroundings, potentially by a selective pattern to fit the metabolism demands of the hypoperfused tissue, or by increasing blood perfusion in hypoperfused tissues selectively and not influencing the non-hypoperfused tissues, as SA did not significantly affect CBV in normal perfused patients. Baron et al (37) found previously that oxygen extraction fraction (OEF) increased from the normal value of approximately 40 to $>80 \%$ in the area of penumbra in a hemodynamic cerebral ischemia patient with positron emission tomography. Furthermore, with the ischemia-reperfusion experiment model in cats, reversible middle cerebral artery (MCA) occlusion 

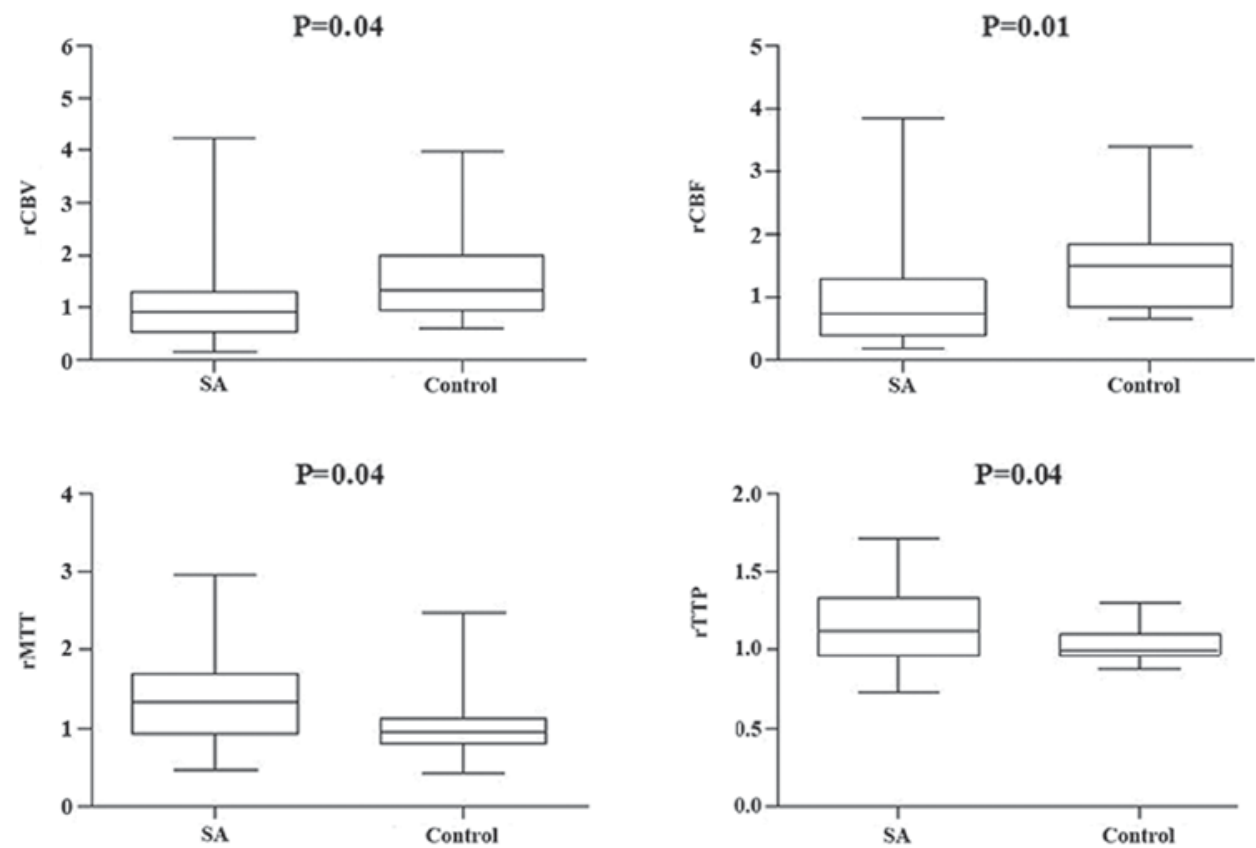

Figure 11. Relative perfusion-weighted magnetic resonance imaging parameters of the diffusion-weighted magnetic resonance imaging lesion in hypoperfused patients after 14 days of treatment. rCBV, relative cerebral blood volume; rCBF, relative cerebral blood flow; rMTT, regional mean transit time; rTTP, regional time to peak; SA, salvianolic acid.
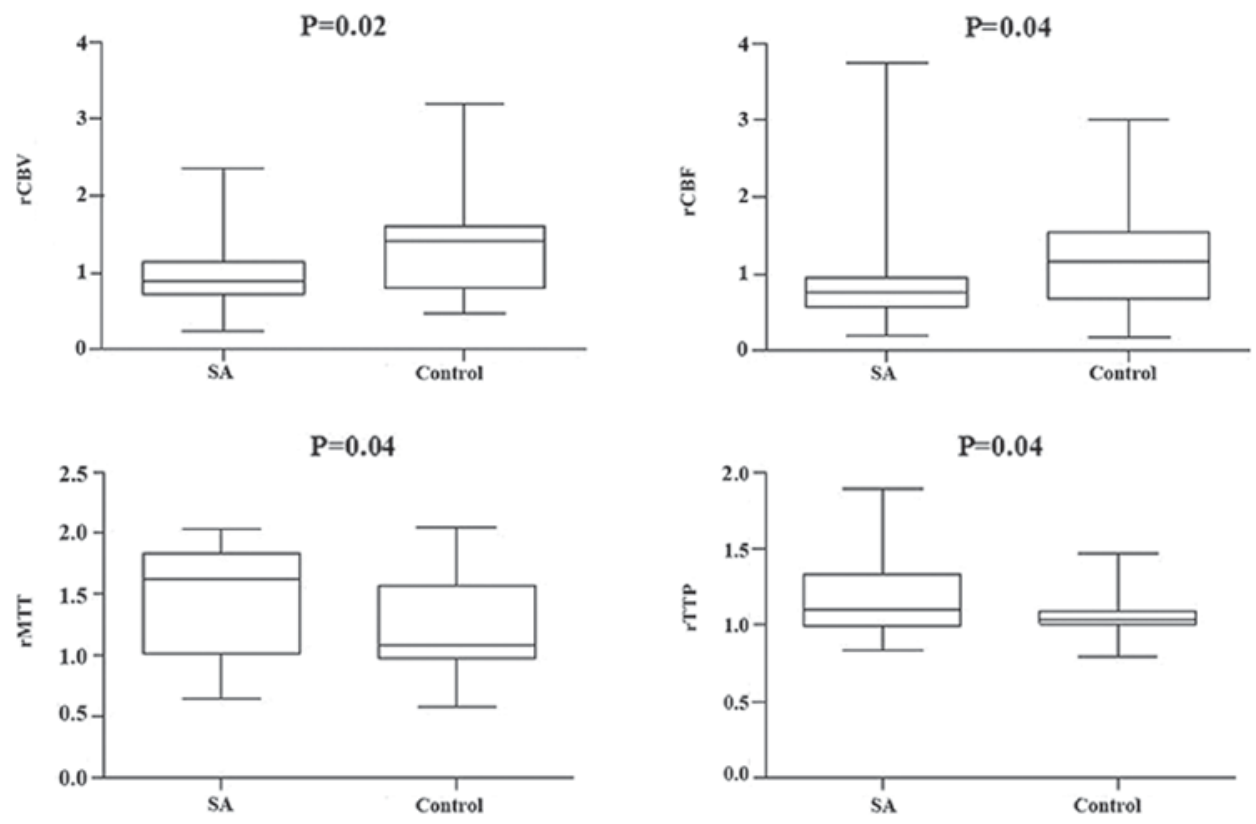

Figure 12. Relative perfusion-weighted magnetic resonance imaging parameters of the surrounding region of the diffusion-weighted magnetic resonance imaging lesion in hypoperfused patients after 14 days of treatment. rCBV, relative cerebral blood volume; rCBF, relative cerebral blood flow; rMTT, regional mean transit time; rTTP, regional time to peak; SA, salvianolic acid.

occurred by reopening the MCA after 60 min (37). Heiss (38) previously reported that when the OEF remained elevated throughout the ischemic episode, reperfusion prevented large infarcts involving cortical areas, and if the initial OEF increase disappeared during ischemia, extended postischemic hyperperfusion-accompanied large infarcts developed. These findings suggest that reperfusion may only fit the metabolic demands of hypoperfused tissues, and consequently, a favorable outcome was obtained. Therefore, the different energy requirements for the maintenance of membrane function and for the propagation of information may result in different blood flow volumes supplied for the preservation of neuronal function and morphological integrity. The present study indicated that SA treatment may be an effective reperfusion treatment for the hypoperfused tissues when administered $<72 \mathrm{~h}$ following the onset of symptoms as it responds appropriately to metabolic demands and consequently provides an improved outcome compared with the control. 
A

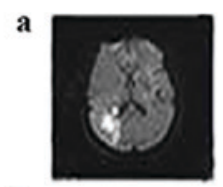

b

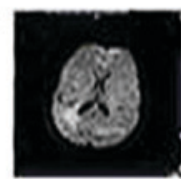

B

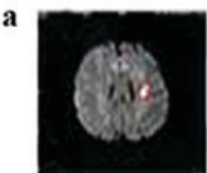

b

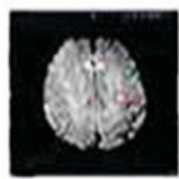

DWI
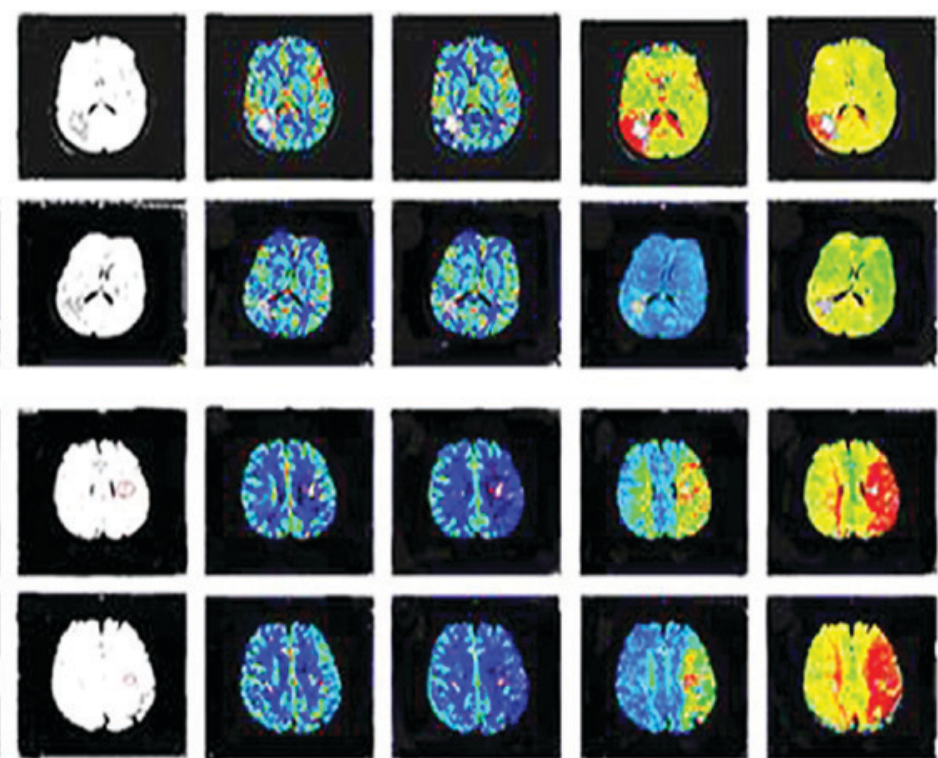

Processed DWI PWI-DWI CBV PWI-DWI CBF PWI-DWI MTT PWI-DWI TT

Figure 13. Illustration of penumbra changes following SA treatment. (A) A 48-year old male who presented with left visual field defect for 3 days. Acute infarction in right occipital lobe was identified by DWI (DWI, Aa). Penumbra surrounding the DWI lesion was presented at admission (PWI-DWI TTP; Aa) and almost disappeared following treatment with SA at the 3-month follow up (PWI-DWI TTP; Ab). (B) Case B was a 53-year old male. The first symptom was right extremity weakness for 2 days. Acute left parietal lobe infarction was identified on admission using DWI (DWI; Ba) and marked penumbra was observed (PWI-DWI TTP; Ba). These observations did not change following treatment with SA even though DWI lesion was attenuated at the 3-month follow up (PWI-DWI TTP; Bb). DWI, diffusion-weighted magnetic resonance imaging; PWI, perfusion-weighted magnetic resonance imaging; CBV, cerebral blood volume; CBF, cerebral blood flow; MTT, mean transit time; TTP, time to peak; SA, salvianolic acid.

When compared with the different responsible arteries, in the ICA territory, SA also appeared to have greater benefits in improving the perfusion of the ischemic core and ischemic penumbra compared with that in the VBA territory. These findings suggest that microcirculation compensation may be a potential mechanism associated with acute stroke treatment with SA. However, further studies are required to fully elucidate this.

The present study indicated that blood perfusion in ischemic core and it's surrounding was improved in hypoperfused tissues following SA treatment. Similar changes were identified in the neurological deficits using NIHSS and mRS. No significant difference was indicated in the NIHSS between the SA and control group at admission; however, a significant decrease in NIHSS was observed in the SA group at the 3-month follow-up compared with that in the control group, which indicated that the SA elicited a neurological protective effect on ischemic brain tissue, and this may be associated with microcirculation compensation. Additionally, the rate of patients with a favorable outcome in the SA group at the 3-month follow-up was significantly increased compared with that in the control group, which suggested that SA improved the neurological defect, potentially due to an improvement in blood supply in the ischemic brain tissue caused by an increase in CBV. The restoration of the blood flow, either antegrade or retrograde, may save the ischemic tissue (16). Mokin et al (39) retrospectively reviewed cases of acute ischemic stroke due to MCA M1 segment occlusion, and associated the favorable outcome with preintervention CBV values. The findings concluded that preintervention CBV values may be used as a predictor of the outcome in patients undergoing intra-arterial stroke therapies (39). Therefore, CBV in brain tissue expressed

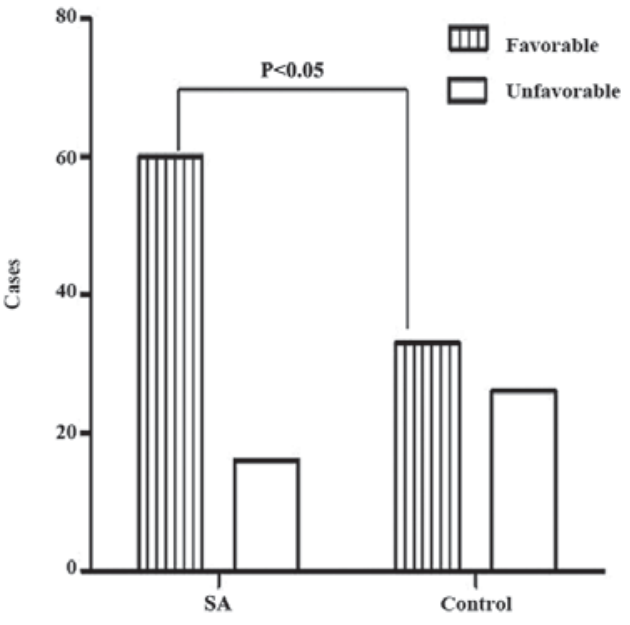

Figure 14. Outcome at 3-month follow-up dichotomized by the modified Rankin Scale. SA, salvianolic acid.

by rCBV in the present study may be a useful indicator of reperfusion in the ischemic region and may be used as criteria to assess the therapeutic effect of drugs in acute stroke therapy.

In addition to increased $\mathrm{CBV}$ in the ischemic region following treatment with SA, decreased $\mathrm{rCBF}$ and increased rMTT were also observed in the present study when compared with that in controls in ICA or in hypoperfusion patients, which indicates longer blood perfusion time. In the control group, significantly increased $\mathrm{rCBV}$ and $\mathrm{rCBF}$ and significantly decreased rMTT were observed compared with the SA group following treatment either in ICA as the responsible vessel or in hypoperfusion patients, implying a shorter blood perfusion time and blood traveling a shorter 
Table VI. Speculated CBV at admission.

\begin{tabular}{llcc}
\hline Group & \multicolumn{1}{c}{ ROI } & rCBV & CBV (\%) \\
\hline SA & DWI & $1.27 \pm 0.59$ & 73 \\
Control & DWI & $1.21 \pm 0.68$ & 79 \\
SA & Surrounding & $1.02 \pm 0.56$ & 98 \\
Control & Surrounding & $1.01 \pm 0.55$ & 99 \\
\hline
\end{tabular}

DWI, diffusion-weighted magnetic resonance imaging lesion; surrounding, surroundings of DWI lesion; ROI, region of interest; $\mathrm{rCBV}$, relative cerebral blood volume; $\mathrm{CBV}$, cerebral blood volume; SA, salvianolic acid.

Table VII. Speculated CBV following treatment.

\begin{tabular}{lllc}
\hline Group & \multicolumn{1}{c}{ ROI } & rCBV & CBV $(\%)$ \\
\hline SA & DWI & $1.29 \pm 0.80$ & 71 \\
Control & DWI & $1.45 \pm 1.08$ & 55 \\
SA & Surrounding & $1.05 \pm 0.57$ & 95 \\
Control & Surrounding & $1.33 \pm 0.60$ & 67 \\
\hline
\end{tabular}

DWI, diffusion-weighted magnetic resonance imaging lesion; Surrounding, surroundings of DWI lesion; ROI, region of interest; $\mathrm{rCBV}$, relative cerebral blood volume; $\mathrm{CBV}$, cerebral blood volume; SA, salvianolic acid.

Table VIII. Speculated CBV after treatment in patients with hypoperfusion at admission.

\begin{tabular}{llcc}
\hline Group & \multicolumn{1}{c}{ ROI } & rCBV & CBV (\%) \\
\hline SA & DWI & $1.07 \pm 0.78$ & 93 \\
Control & DWI & $1.54 \pm 0.81$ & 46 \\
SA & Surrounding & $0.98 \pm 0.51$ & 102 \\
Control & Surrounding & $1.39 \pm 0.68$ & 61 \\
\hline
\end{tabular}

DWI, diffusion-weighted magnetic resonance imaging lesion; surrounding, surroundings of DWI lesion; ROI, region of interest; rCBV, relative cerebral blood volume; $\mathrm{CBV}$, cerebral blood volume; SA, salvianolic acid.

distance by other vessels as opposed to the capillaries (such as the arteries and veins).

$\mathrm{SA}$, consists of the water-soluble components isolated from the roots of Salvia miltiorrhiza Bunge, which contains $1 \%$ SA A, $57 \%$ SA B, 37\% rosmarinic acid and 5\% other acids, and is a Chinese herb widely used for the treatment of stroke (40). The use of SA was approved in 2011 by the Chinese State food and Drug administration (Z20110011) for the treatment of ischemic stroke (41). Previous findings have indicated that SA inhibits lipid peroxidation, scavenges free radicals and protects neural cells against injuries caused by anoxia $(42,43)$. In the present study, SA improved the perfusion of ischemic brain tissues selectively, and induced a favorable outcome compared
Table IX. Speculated CBV following treatment in patients with ICA responsible artery.

\begin{tabular}{lllr}
\hline Group & \multicolumn{1}{c}{ ROI } & rCBV & CBV (\%) \\
\hline SA & DWI & $1.02 \pm 0.46$ & 98 \\
Control & DWI & $1.50 \pm 1.16$ & 50 \\
SA & Surrounding & $0.96 \pm 0.43$ & 104 \\
Control & Surrounding & $1.33 \pm 0.69$ & 67 \\
\hline
\end{tabular}

DWI, DWI lesion; Surrounding, surroundings of DWI lesion; ROI, region of interest; rCBV, relative cerebral blood volume; $\mathrm{CBV}$, cerebral blood volume; SA, salvianolic acid; ICA, internal cranial artery.

Table X. NIHSS and mRS score.

\begin{tabular}{lccc}
\hline & \multicolumn{2}{c}{ NIHSS } \\
\cline { 2 - 3 } Group & Admission & 90 -day & $\begin{array}{c}\text { mRS } \\
90 \text {-day }\end{array}$ \\
\hline SA & $8.43 \pm 6.05$ & $3.25 \pm 4.67$ & $1.26 \pm 1.58$ \\
Control & $9.12 \pm 5.98$ & $5.76 \pm 3.82$ & $2.01 \pm 1.58$ \\
P-value & 0.47 & 0.001 & 0.005 \\
\hline
\end{tabular}

SA, salvianolic acid; NIHSS, National Institutes of Health Stroke Scale; mRS, modified Rankin Scale.

with the controls at 3-month follow-up. Based on the present findings, microcirculation compensation may be a potential mechanism associated with the effect of SA on acute stroke. Further studies are required, particularly in vivo experiments, to fully explore the effects of microcirculation compensation in acute stroke.

The present study did have some limitations. Firstly, the study was semi-qualitative. However, relative PWI parameters are simply obtained and it has been observed that speculated CBV from rCBV is similar to that from volumetric assessment (44). In a previous study by the present authors, using the speculation method, it was revealed that $118 \%$ of the contralateral CBV appeared in normal perfused patients and $77 \%$ in hypoperfused patients within DWI lesions; and surrounding the DWI lesion $121 \%$ of the contralateral CBV in normal perfused patients and $90 \%$ in hypoperfused patients, respectively; which suggests that $>90 \%$ of the contralateral CBV may fit the metabolic demands of the hypoperfused tissues, and $>120 \%$ of the contralateral CBVs may maintain a normal perfusion map (45). In the present study, increasing CBV appeared in the SA group after treatment whether in DWI lesions or it's surrounding with patients of hypoperfusion or ICA as the responsible artery but does not meet the $120 \%$ criteria to reverse the hypoperfusion completely in the PWI map in all patients Secondly, visual assessment is not as accurate as volumetric assessment; however, hypoperfusion was easily detected using visual assessment. Furthermore, in the present study, the ROI was selected from a single time point of the PWI map and therefore not all time points were considered, which increased the extent of selection error. Additionally, the authors suggest that the 
increased CBV in ischemic brain tissue following treatment with SA was due to surrounding circulation compensation as opposed to the normal microcirculation perfusion, however animal experiments are required to confirm.

In conclusion, the present results indicate that SA treatment may improve the perfusion of ischemic brain tissues, including the ischemic core and penumbra in ICA or hypoperfused patients with acute stroke. Furthermore, these findings suggest that SA may be used to improve neurological function and obtain favorable outcomes for patients that have suffered with acute stroke.

\section{Competing interests}

All authors declare that there are no competing interests.

\section{References}

1. Roth GA, Johnson C, Abajobir A, Abd-Allah F, Abera SF Abyu G, Ahmed M, Aksut B, Alam T, Alam K, et al: Global, regional, and national burden of cardiovascular diseases for 10 causes, 1990-2015. J Am Coll Cardio 4: 1-25, 2017.

2. Vagal A, Sanelli P, Sucharew H, Alwell KA, Khoury JC, Khatri P, Woo D, Flaherty M, Kissela BM, Adeoye O, et al: Age, sex, and racial differences in neuroimaging use in acute stroke: A population-based study. AJNR Am J Neuroradiol 38: 1905-1910, 2017.

3. Kim AS, Cahill E and Cheng NT: Global stroke belt: Geographic variation in stroke burden worldwide. Stroke 46: 3564-3570, 2015.

4. Long X, Lou Y, Gu H, Guo X, Wang T, Zhu Y, Zhao W, Ning X, Li B, Wang J and An Z: Mortality, recurrence, and dependency rates are higher after acute ischemic stroke in elderly patients with diabetes compared to younger patients. Front Aging Neurosci 8: 142, 2016.

5. Gan Y, Wu J, Zhang S, Li L, Yin X, Gong Y, Herath C, Mkandawire N, Zhou Y, Song X, et al: Prevalence and risk factors associated with stroke in middle-aged and older Chinese: A community-based cross-sectional study. Sci Rep 7: 9501, 2017.

6. Motyer R, Asadi H, Thornton J, Nicholson P and Kok HK: Current evidence for endovascular therapy in stroke and remaining uncertainties. J Intern Med 283: 2-15, 2018.

7. Wey HY, Desai VR and Duong TQ: A review of current imaging methods used in stroke research. Neurological Res 35: 1092-1102, 2013.

8. An H, Ford AL, Eldeniz C, Chen Y, Vo KD, Zhu H, Powers WJ, Lin W and Lee JM: Reperfusion beyond 6 hours reduces infarct probability in moderately ischemic brain tissue. Stroke 47: 99-105, 2016

9. Mishra NK, Albers GW, Davis SM, Donnan GA, Furlan AJ, Hacke W and Lees KR: Mismatch-based delayed thrombolysis: A meta-analysis. Stroke 41: e25-e33, 2010.

10. Albers GW: Expanding the window for thrombolytic therapy in acute stroke. The potential role of acute MRI for patient selection. Stroke 30: 2230-2237, 1999.

11. Kim SJ, Seok JM, Bang OY, Kim GM, Kim KH, Jeon P, Chung CS, Lee KH, Alger JR and Liebeskind DS: MR mismatch profiles in patients with intracranial atherosclerotic stroke: A comprehensive approach comparing stroke subtypes. J Cereb Blood Flow Metab 29: 1138-1145, 2009.

12. Neumann-Haefelin T, Wittsack HJ, Wenserski F, Siebler M, Seitz RJ, Mödder U and Freund HJ: Diffusion- and perfusion-weighted MRI. The DWI/PWI mismatch region in acute stroke. Stroke 30: 1591-1597, 1999.

13. Galinovic I, Ostwaldt AC, Soemmer C, Bros H, Hotter B, Brunecker P, Schmidt WU, Jungehülsing J and Fiebach JB: Search for a Map and threshold in perfusion MRI to accurately predict tissue fate: A protocol for assessing lesion growth in patients with persistent vessel occlusion. Cerebrrovasc Dis 32: 186-193, 2011.

14. Mishra NK, Albers GW, Christensen S, Marks M, Hamilton S, Straka M, Liggins JT, Kemp S, Mlynash M, Bammer R, et al: Comparison of magnetic resonance imaging mismatch criteria to select patients for endovascular stroke therapy. Stroke 45: 1369-1374, 2014.
15. Prabhakaran S, Ruff I and Bernstein RA: Acute stroke intervention: A systematic review. JAMA 313: 1451-1462, 2015.

16. Davis S, Campbell B, Christensen S, Ma H, Desmond P, Parsons M, Levi C, Bladin C, Barber PA and Donnan G: Perfusion/Diffusion mismatch is valid and should be used for selecting delayed interventions. Transl Stroke Res 3: 188-197, 2012.

17. Sun K, Fan J and Han J: Ameliorating effects of traditional Chinese medicine preparation, Chinese materia medica and active compounds on ischemia/reperfusion induced cerebral microcirculatory disturbances and neuron damage. Acta Pharm Sin B 5: 8-24, 2015.

18. Chien MY, Chuang CH, Chern CM, Liou KT, Liu DZ, Hou YC and Shen YC: Salvianolic acid A alleviates ischemic brain injury through the inhibition of inflammation and apoptosis and the promotion of neurogenesis in mice. Free Radic Biol Med 99: 508-519, 2016.

19. Zhuang P, Wan Y, Geng S, He Y, Feng B, Ye Z, Zhou D, Li D, Wei H,Li H,et al: Salvianolic acids for injection (SAFI) suppresses inflammatory responses in activated microglia to attenuate brain damage in focal cerebral ischemia. J Ethnopharmacol 198: 194-204, 2017.

20. Feng SQ, Aa N, Geng JL, Huang JQ, Sun RB, Ge C, Yang ZJ, Wang LS, Aa JY and Wang GJ: Pharmacokinetic and metabolomic analyses of the neuroprotective effects of salvianolic acid A in a rat ischemic stroke model. Acta Pharmacol Sin 38: 1435-1444, 2017.

21. Murphy S, Thomas NJ, Gertz SJ, Beca J, Luther JF, Bell MJ, Wisniewski SR, Hartman AL and Tasker RC: Tripartite stratification of the Glasgow coma scale in children with severe traumatic brain injury and mortality: An analysis from a multi-center comparative effectiveness study. J Neurotrauma Feb 27, 2017.

22. Stefanovic Budimkic M, Pekmezovic T, Beslac-Bumbasirevic L, Ercegovac M, Berisavac I, Stanarcevic P, Padjen V and Jovanović DR: Long-term prognosis in ischemic stroke patients treated with intravenous thrombolytic therapy. J Stroke Cerebrovasc Dis 26: 196-203, 2017.

23. Suwanwela NC, Chutinet A, Mayotarn S, Thanapiyachaikul R, Chaisinanunkul N, Asawavichienjinda T, Muengtaweepongsa S, Nilanont Y, Samajarn J, Watcharasaksilp K, et al: A randomized controlled study of intravenous fluid in acute ischemic stroke. Clin Neurol Neurosurg 161: 98-103, 2017.

24. Siemonsen S, Fitting T, Thomalla G, Krutzelmann A and Fiehler J: Visual assessment of magnetic resonance imaging perfusion lesions in a large patient group. Clin Neuroradiol 22: 305-313, 2012.

25. Østergaard L: Principles of cerebral perfusion imaging by bolus tracking. J Magn Reson Imaging 22: 710-717, 2005.

26. Robertson CA, McCabe C, Gallagher L, Lopez-Gonzalez Mdel R, Holmes WM, Condon B, Muir KW, Santosh C and Macrae IM: Stroke penumbra defined by an MRI-based oxygen challenge technique: 1. Validation using [14C]2-deoxyglucose autoradiography. J Cere Blood Flow Metab 31: 1778-1787, 2011.

27. The National Institute of Neurological Disorders and Stroke rt-PA Stroke Study Group: Tissue plasminogen activator for acute ischemic stroke. N Engl J Med 333: 1581-1587, 1995.

28. Ciccone A, Valvassori L, Ponzio M, Ballabio E, Gasparotti R, Sessa M, Scomazzoni F, Tiraboschi P and Sterzi R; SYNTHESIS Investigators: Intra-arterial or intravenous thrombolysis for acute ischemic stroke? J Neurointerv Surg 2: 74-79, 2010.

29. Berkhemer OA, Fransen PS, Beumer D, van den Berg LA, Lingsma HF, Yoo AJ, Schonewille WJ, Vos JA, Nederkoorn PJ, Wermer MJ, et al: A randomized trial of intra-arterial treatment for acute ischemic stroke. N Engl J Med 372: 11-20, 2015.

30. Goyal M, Demchuk AM, Menon BK, Eesa M, Rempel JL, Thornton J, Roy D, Jovin TG, Willinsky RA, Sapkota BL, et al: Randomized assessment of rapid endovascular treatment of ischemic stroke. N Engl J Med 372: 1019-1030, 2015.

31. Campbell BC, Mitchell PJ, Kleinig TJ, Dewey HM, Churilov L, Yassi N, Yan B, Dowling RJ, Parsons MW, Oxley TJ, et al: Endovascular therapy for ischemic stroke with perfusion-imaging selection. N Engl J Med 372: 1009-1018, 2015.

32. Saver JL, Goyal M, Bonafe A, Diener HC, Levy EI, Pereira VM, Albers GW, Cognard C, Cohen DJ, Hacke W, et al: Solitaire ${ }^{\mathrm{TM}}$ with the intention for thrombectomy as primary endovascular treatment for acute ischemic stroke stroke (SWIFT PRIME) trial: Protocol for a randomized, controlled, multicenter study comparing the Solitaire revascularization device with IV tPA with IV tPA alone in acute ischemic stroke. Int J Stroke 10: 439-448, 2015. 
33. Schwamm LH, Ali SF, Reeves MJ, Smith EE, Saver JL, Messe S, Bhatt DL, Grau-Sepulveda MV, Peterson ED and Fonarow GC: Temporal trends in patient characteristics and treatment with intravenous thrombolysis among acute ischemic stroke patients at Get with the Guidelines-Stroke hospitals. Circ Cardiovase Qual Outcomes 6: 543-549, 2013.

34. Menon BK, Saver JL, Goyal M, Nogueira R, Prabhakaran S, Liang L, Xian Y, Hernandez AF, Fonarow GC, Schwamm L and Smith EE: Trends in endovascular therapy and clinical outcomes within the nationwide get with the guidelines-stroke registry. Stroke 46: 989-995, 2015

35. Fujioka M, Okuchi K, Iwamura A, Taoka T and Siesjö BK A mismatch between the abnormalities in diffusion- and susceptibility-weighted magnetic resonance imaging may represent an acute ischemic penumbra with misery perfusion. J Stroke Cerebrovasc Dis 22: 1428-1431, 2013.

36. Gersing AS, Ankenbrank M, Schwaiger BJ, Toth V, Janssen I, Kooijman H, Wunderlich S, Bauer JS, Zimmer C and Preibisch C: Mapping of cerebral metabolic rate of oxygen using dynamic susceptibility contrast and blood oxygen level dependent MR imaging in acute ischemic stroke. Neuroradio 57: 1253-1261, 2015.

37. Baron JC, Bousser MG, Rey A, Guillard A, Comar D and Castaigne P: Reversal of focal 'misery-perfusion syndrome' by extra-intracranial arterial bypass in hemodynamic cerebral ischemia. A caes study with $15 \mathrm{O}$ positron emission tomography. Stroke 12: 454-459, 1981.

38. Heiss WD: The ischemic penumbra: Correlates in imaging and implications for treatment of ischemic stroke. The Johann Jacob Wepfer award 2011. Cerebrovasc Dis 32: 307-320, 2011.
39. Mokin M, Morr S, Fanous AA, Shallwani H, Natarajan SK, Levy EI, Snyder KV and Siddiqui AH: Correlation between cerebral blood volume values and outcomes in endovascular therapy for acute ischemic stroke. J NeuroInterv Surg 7: 705-708, 2015.

40. Ren DC,Du GH and Zhang JT: Inhibitory effect of salvianolic acids on endothelial cells damage induced by hydrogen peroxide. Chin J Pharmacol Toxicol 17: 333-337, 2003.

41. Tang H, Pan CS, Mao XW, Liu YY, Yan L, Zhou CM, Fan JY, Zhang SY and Han JY: Role of NADPH oxidase in total salvianolic acid injection attenuating ischemia-reperfusion impaired cerebral microcirculation and neurons: Implication of AMPK/AKt/PKC. Microcirculation 21: 615-627, 2014.

42. Chen YH, Du GH and Zhang JT: Salvianolic acid B protects brain against injuries caused by ischemia-reperfusion in rats. Acta Pharmacol Sin 21: 463-466, 2000.

43. Hou S, Zhao MM, Shen PP, Liu XP, Sun Y and Feng JC: Neuroprotective effect of salvianolic acids against cerebral ischemia/reperfusion injury. Int J Mol Sci 17: pii: E1190, 2016.

44. Knash M, Tsang A, Hameed B, Saini M, Jeerakathil T, Beaulieu C, Emery D and Butcher K: Low cerebral blood volume is predictive of diffusion restriction only in hypeeracute stroke. Stroke 41: 2795-2800, 2010

45. Liu Y, Peng JW and Yu LF: Changes of cerebral perfusion and potential targets for intervention in acute ischemic stroke. Chin J Pract Nerv Dis 20: 11-16, 2017 (In Chinese). 